\title{
Impact of Educational Training Program on Nurse's knowledge and practice for Intensive Care Unit Patient Undergoing Endotracheal Intubation
}

\author{
Abdulnasser A Haza'a, Mona A Mohammed, Mervat A Abdel-Aziz \& Hany A Ibrahim, \\ Clinical Nurse Specialist in Kuwait University Hospital, Yemen. \\ Lecturer of critical care Nursing, Faculty of Nursing, Assiut University, Egypt. \\ Lecturer of critical care Nursing, Faculty of Nursing, Assiut University, Egypt. \\ Professor of Anesthesia, Faculty of Medicine, Assiut University, Egypt.
}

\begin{abstract}
Background: Education programs are considered for providing nurses with theoretical and technical information needed to acquire new skills and knowledge. Aim: to assess nurses` knowledge and practice regarding patients who had an endotracheal tube and evaluate the effect of implementing education program on nurses practice and patient's complications. A Quasi-experimental design. This study was carried out in Trauma and General Intensive Care Unit. The sample of this study consisted of 60 nurses and 120 patients who had endotracheal tube pre/post implementing the program. Tools utilized for data collection were nursing questionnaire sheet, observation checklist sheet, and Patient assessment sheet. The results There were statistical significant differences $(\mathrm{P}<0.000)$ in the total nurses knowledge scores regarding endotracheal tube care, pre- implementation was compared with postimplementation and There were statistically significant differences $(\mathrm{P}<0.000)$ in total nurses practice scores regarding endotracheal tube care pre- implementation was compared with post- implementation. The patient complication was less oral inflammation absence $70 \%$ post-implementing the program. In conclusion: there is the statistically significant difference between the nurse knowledge and practice in pre/post implementing the program. Improving nurses' knowledge and practice have a favorable effect in preventing post-endotracheal tube care complications.
\end{abstract}

Keywords: Endotracheal tube, Knowledge, Practice, educational \& training program.

\section{Introduction}

Endotracheal intubation is one of the most commonly performed procedures in the intensive care unit. It is an essential life-saving intervention; however, complications during airway management in such patients may precipitate a crisis (Divatia et al., 2011).

Endotracheal intubation is an advanced airway procedure where an orotracheal tube is placed under direct vision through the larynx into the trachea. It has the advantage of providing a protected airway whilst enabling ventilation, a route for oxygenation and suctioning (Agr, 2011).

Several complications can occur while the ETT is in place, including aspiration and ventilator-associated pneumonia, nasal and oral inflammation or ulceration, sinusitis and otitis, laryngeal and tracheal injuries, tube obstruction and displacement (Urden et al., 2014).

Critical care is a complex specialty developed to serve the diverse health care needs of patients with actual potentially life-threatening conditions. The professional practice in a high-risk critical care setting requires specialized knowledge, advanced practices, clinical experience and problem-solving abilities to assess monitor and effectively respond to the needs of critically ill patients (Jansson M. 2014).

The nursing role for the intubated patient requires care to ensure airway patency and prevent complications until he can maintain independent ventilation. This care includes frequent assessment of airway stats, maintenance of proper cuff pressure to prevent tissue ischemia and necrosis, repositioning of the tube to avoid traumatic manipulation, and constant monitoring for complication (Miller \& Pardo, 2011).

\section{The aim of the study}

To assess nurses` knowledge and practice regarding patients who had an endotracheal tube and evaluate the effect of implementing education program on nurses knowledge, practice and patient's complications.

\section{Research hypothesis}

To fulfill the aim of this study, the following research hypotheses were formulated

- The post mean knowledge scores of nurses will be higher than pre mean knowledge scores.

- The post-practice score of nurses will be higher than the pre mean practice scores. 
- A positive relationship will exist between knowledge and practice score obtained by nurses who had developed endotracheal tube care.

- The incidence of endotracheal tube complications for a patient who had endotracheal tube care implementation will be less than that preimplementation care.

\section{Significance of the study}

The significant of this study, from researcher's clinical experience it was observed that endotracheal intubation tube care is a complex procedure and was numerous attendant risk and complication associated with it Endotracheal tube complications increase morbidity, hospital cost and mortality of trauma patient who require intubation during intensive care unit stay, which makes the health care providers do great efforts to decrease the incidence of this complication. They should have the knowledge, good practice and be skillful in dealing with these complications. Therefore, for these reasons, there is a clear need for more effective nurse education regarding endotracheal tube care.

\section{Subject \& Method}

\section{Research design}

The quite experimental design has been utilized in this study.

\section{Setting}

The study was conducted in the trauma ICU (12beds) and general ICU (5beds) in Assiut University Hospital.

\section{Subjects}

The sample consists of two groups

- A convenience sample of 60 nurses (43 working in the trauma intensive care unit and 17 working, in general, intensive care unit). In addition to 120 adult patients who had an endotracheal tube before and after implemented endotracheal tube nursing care. Patients selected according to the following the age of (18-60) years, the absence of chronic lung disease, a recent trauma patient, mechanical ventilation.

Exclusion criteria: History of previous trauma, readmission to the general and trauma ICU.

\section{Study tools}

Data pertinent to the study were collected, utilizing the following four tools:

\section{As regard the nurse's}

Tool one: Nurses questionnaire sheet (Pre/post):

It was developed by the researcher based on current national and international an extensive review of the literature (Urden et al., 2014).

This tool was used to assess their knowledge regarding endotracheal tube care procedure and used prior to and immediately after the implementation of the educational program for nurses, it consists of six main parts:

- Socio-demographic data as (name, age, marital status, qualification, years of experience and previously attended training opportunities about post-endotracheal intubation care.

- Basic knowledge about endotracheal intubation covered the following items; definition, purposes, indications, advantage and disadvantage, and complication (13 questions).

- Knowledge related to nursing practice for preparation endotracheal intubation (6 questions).

- Knowledge related to nurse practice during endotracheal intubation (8 questions).

- Knowledge related to nursing practice after endotracheal intubation care (21 question).

- Knowledge related to nursing practice for prevention of infection with endotracheal intubation care (5 questions).

Scoring system: Each right answer was given score according to answer the total scores were 52 degrees those who obtained $<60 \%$ were considered having an unsatisfactory level of knowledge. While those who obtained $\geq 60$ was considered having a satisfactory level of knowledge.

Tool two: Observation checklist sheet (Pre/post)

Observational checklists for assessment of nurses level of skills in providing endotracheal tube care, which included frequency, different methods of solution: (endotracheal tube care procedure 163 items checked), assess the patient immediately pre endotracheal tube care (5 items checked), endotracheal tube care procedure (27 items checked), arterial blood gas analysis procedure (31 items checked),oral care procedure (21 items checked), endotracheal suctioning procedure (37 items checked), endotracheal tube cuff care procedure(15 items checked), mechanical ventilation procedure (7 items checked), reevaluation care procedure (6 items checked), documentation(14 items checked) every step takes score 1 point.

The scoring system of observation checklist sheet was 163 degree each item in checklist was scored as one degree for each step that done and zero for each step that not done. Scoring system translated into results into adequate and inadequate done, adequately done include steps that done and inadequately done include steps that not done Scores $\geq 60 \%$ was graded as an adequate level of skills. Scores $<60$ were graded as inadequate of level skills.

Tool three: Patient's assessment sheet The assessment sheet covered the following

- Biosocial demographic data and clinical data about the patient such as patient's code, age, sex, diagnosis, past history, chronic disease. 
- Hemodynamic includes (Diastolic, systolic pressure, and pulse rate). Respiratory assessment includes (Respiratory rate and rhythm, breathing sound, secretions, temperature). Mechanical ventilation parameters include: (Mode, respiratory rate, tidal volume, $\mathrm{FiO}_{2}$ ).

- Glasgow Coma Scale to the assessment of the level of consciousness.

- Laboratory investigations include arterial blood gasses and blood culture.

- Endotracheal tube complications that may develop for patients who had an endotracheal tube.

Tool four: Educational booklet: For nurses' knowledge and practice about endotracheal tube The education program was developed by the researcher based on the previous assessment of nurses' knowledge and practices. Available resources and review of relevant literature.

\section{Methodology}

Preparatory phase

- An Official permission from the faculty of nursing to conduct the study was delivered to the hospital authorities (head of departments of trauma and general intensive care unit) in Assuit university hospital and approval to conduct this study was obtained.

- Ethical considerations: the nature and purpose of the study were explained to every nurse

- The research proposal was approved by Ethical committee in the faculty of nursing.

- There is a risk for study subject during application of the research.

- Written consent was obtained from patients or guidance that are willing to participate in the study, after explaining the nature and purpose the study.

- The study follows of the common ethical principles in clinical research.

- Confidentiality and anonymity were assured.

- Study subject had the right to refuse to participate and or withdraw from the study without any rational any time.

- Study subject privacy was considered during collection of data.

- Content validity: The tools were tested for content validity of research by Jury of 5 expertise from the field of staff critical care ( 2 medical professors, and 1 anesthesia assistant professor) and nursing educators (2 professors).

- A pilot study carried out before starting of data collection to test the feasibility and the clarity of the study tools on $10 \%$ of the sample, the analysis of pilot study define the modification required in the tool used, and the necessary modification was done prior to data collection. The studied subjects were excluded from the actual study.
- Reliability: Knowledge and practice about Endotracheal Tube Care were established (Cronbach's Alpha >83). Internal consistency reliability for observation checklist was established (Cronbach's Alpha <91).

- Review of current study and past, local and international related in the various aspects of the problems using books, articles, periodically and magazines were done. The proposed study setting assessed the effect of the endotracheal tube care educational program on Knowledge and practice of critical care nurses.

- Educational program v/as conducted by the researcher for ICU nursing (60) about endotracheal tube care who were working in trauma and general intensive care unit in Assuit university hospital.

- The total sample was divided into 12subgroups consisted of 5 nurses for each session.

Implementing phase

All the nurses have completed the pretest, attended the educational session and finished the posttest questionnaire. Questionnaire sheet was developed by the researcher and used to assess nurse's level of knowledge about endotracheal tube care.

Observational checklists were developed by the researcher to assess nurse's level of practices in providing endotracheal tube care.

The educational program has been implemented in eight sessions

Three theoretical sessions about the following

- Description the anatomy and physiology of the respiratory system and define endotracheal intubation (30 minutes).

- Enumerate indications and purpose of endotracheal intubation (30 minutes).

- Identify the advantage and disadvantage with the complications of endotracheal intubation (30 minutes).

Five clinical sessions about the following

- A technique for assessing the patient immediately pre endotracheal tube car (5 minutes).

- ETT care and cuff pressure monitoring (10 minutes).

- Suction technique from the oropharyngeal cavity and from the ETT (10 minutes).

- The technique of oral care for mechanically ventilated patients (10 minutes).

- Arterial blood gas analysis technique, mechanical ventilation preparation, reevaluation assessment and documentation for endotracheal tube care implementation (15 minutes).

\section{Procedure}

- Each theoretical session was carried out in class to include all nurses. All the topics were presented in the form of power point program. 
- Theoretical sessions started with discussion (10 minutes) to assess nurse's feedback of knowledge about related topics then the researcher started the education time. After the session break time was given to them (10 minutes) followed with discussion to assess nurse's level of understanding (10 minutes).

- Clinical sessions were conducted first in the clinical lab by using a doll.

- Every session was started first with discussion to assess nurse's feedback about the procedure (5 minutes) then training phase about the definition, indication, frequency of endotracheal tube care, and technique of the procedure (20 minutes).

- Researcher provided teaching material as videos about the procedure to help nurses during demonstrating it. Videos were presented before and after demonstration time.

- Each clinical session was repeated more than once in the same day and in the other day to be sure that every nurse reached accurate skills of the procedure.

- All nurses demonstrated for studied groups the procedure once or more under observation by a researcher in the lab to ensure correct procedure and assess the weak points.

- Each nurse of all studied groups obtained a copy of the educational program in Arabic and English language booklet included all theoretical and practical content.

- The topics included hand out, posters and clinical videos for demonstration of the care provided

- An open channel communication was achieved between researcher and nurses to ensure understanding, answer any question and to verify information and practical skills given.

- The observational checklist was used during data collection to evaluate the nursing level of skills in providing endotracheal tube care and to ensure skills until competency. Each right action would have score 1 according to its importance and the false action had scored zero. As well as the researcher filled the patient assessment sheet (tool III)

- Each group takes one-week training in ICU so that evaluation of the nurse's skills started from the second week of every group

\section{Evaluation phase}

The evaluation of knowledge was done immediately after program implementation by using the same questionnaire sheet (the post-test). The nurse who passed $60 \%$ and more of the questionnaire sheet correctly was considered satisfactory but who passed less than $60 \%$ was considered unsatisfactory.

\section{Statistical Analysis}

Data were collected and analyzed by computer program SPSS, version 19. (SPSS Inc., Chicago, USA). Data expressed as mean, standard deviation, number, and percentage. The t-test is used to determine significant for the numeric variable. The chi-square test is used to determine significant for the non-parametric variable. Also correlation by Pearson Correlation. A probability level of 0.05 was adopted as a level of significance for testing the research hypothesis statistically significant differences were considered when the $\mathrm{P}-$ value was $\leq 0.05$. 


\section{Results}

Table (1): Distribution of studied critical care nurses according to their characteristics (No. $=60$ ).

\begin{tabular}{|c|c|c|c|c|}
\hline \multirow{3}{*}{ Characteristics } & \multicolumn{4}{|c|}{ Units } \\
\hline & \multicolumn{2}{|c|}{ Trauma ICU(No.=43) } & \multicolumn{2}{|c|}{ General ICU(No.=17) } \\
\hline & No. & $\%$ & No. & \\
\hline \multicolumn{5}{|l|}{ Age } \\
\hline Less than $25 y r s$ & 11 & 18.3 & 9 & 15 \\
\hline $25-30 y r s$ & 24 & 40 & 5 & 8.3 \\
\hline More than 30yrs & 8 & 13.3 & 3 & 5 \\
\hline \multicolumn{5}{|l|}{ Marital status } \\
\hline Single & 26 & 43.3 & 10 & 16.7 \\
\hline Married & 17 & 28.3 & 7 & 11.7 \\
\hline \multicolumn{5}{|l|}{ Educational level } \\
\hline Diploma & 14 & 23.3 & 9 & 15 \\
\hline Technical nursing & 13 & 21.7 & 5 & 8.3 \\
\hline Bachelorizes degree & 16 & 26.7 & 3 & 5 \\
\hline \multicolumn{5}{|l|}{ Experience years } \\
\hline $0<1$ & 13 & 21.7 & 5 & 8.3 \\
\hline $1<5$ & 9 & 15 & 2 & 3.3 \\
\hline $5-10$ & 15 & 25 & 7 & 11.7 \\
\hline$>10$ & 6 & 10 & 3 & 5 \\
\hline \multicolumn{5}{|l|}{ Training courses ETT } \\
\hline yes & 11 & 18.3 & 5 & 8.3 \\
\hline No & 32 & 53.3 & 12 & 20 \\
\hline
\end{tabular}

ICU= Intensive care unit

ETT: Endotracheal tube

Table (2): The total mean score percentage of the studied critical care nurses knowledge pre and post of endotracheal tube care implementation $($ No. $=60)$.

\begin{tabular}{|c|c|c|c|c|c|c|c|}
\hline \multirow{4}{*}{ Nurses knowledge } & \multicolumn{7}{|c|}{ Units } \\
\hline & \multicolumn{3}{|c|}{ Trauma ICU $($ No.=43) } & \multicolumn{3}{|c|}{ General ICU (No.=17) } & \multirow[b]{3}{*}{ P1-value } \\
\hline & \multicolumn{2}{|c|}{ Mean \pm S.D } & \multirow{2}{*}{$\begin{array}{c}P \text { - } \\
\text { value }\end{array}$} & \multicolumn{2}{|c|}{ Mean \pm S.D } & \multirow{2}{*}{$\begin{array}{c}\mathrm{P}- \\
\text { value }\end{array}$} & \\
\hline & $\begin{array}{l}\text { Pre- } \\
\text { implementing }\end{array}$ & $\begin{array}{l}\text { Post- } \\
\text { implementing }\end{array}$ & & $\begin{array}{c}\text { Pre- } \\
\text { implementing }\end{array}$ & $\begin{array}{c}\text { Post- } \\
\text { implementing }\end{array}$ & & \\
\hline $\begin{array}{l}\text { Knowledge about } \\
\text { endotracheal } \\
\text { intubation }\end{array}$ & $7.19 \pm 1.71$ & $9.37 \pm 1.72$ & $<.001 *$ & $7.71 \pm 1.93$ & $9.71 \pm 1.36$ & $<.003$ & $<0.001 * * *$ \\
\hline $\begin{array}{c}\text { Preparation } \\
\text { endotracheal } \\
\text { intubation }\end{array}$ & $4.14 \pm 1.04$ & $5.23 \pm 1.36$ & $<.002 *$ & $4.24 \pm 1.39$ & $5.53 \pm 1.23$ & $<.026$ & $<0.001 * * *$ \\
\hline $\begin{array}{c}\text { During } \\
\text { endotracheal } \\
\text { intubation }\end{array}$ & $2.42 \pm .88$ & $3.93 \pm 1.25$ & $<.003 *$ & $2.35 \pm 1.22$ & $3.88 \pm 1.05$ & $<.001$ & $<0.001 * * *$ \\
\hline $\begin{array}{c}\text { After endotracheal } \\
\text { intubation }\end{array}$ & $8.51 \pm 2.53$ & $11.88 \pm 3.37$ & $<.000^{*}$ & $8.24 \pm 2.39$ & $13 \pm 3.46$ & $<.000$ & $<0.001 * * *$ \\
\hline Infection control & $2.33 \pm 0.72$ & $3.56 \pm 0.80$ & $<.004 *$ & $2.59 \pm .87$ & $3.35 \pm 0.61$ & $<.011$ & $<0.001 * * *$ \\
\hline $\begin{array}{c}\text { Overall total } \\
\text { knowledge }(52)\end{array}$ & $24.58 \pm 4.38$ & $34.37 \pm 5.42$ & $<.000^{*}$ & $25.12 \pm 4.4$ & $35.65 \pm 5.52$ & $<.000$ & $<0.001 * * *$ \\
\hline
\end{tabular}

ICU Intensive care unit

Paired sample t-test,

$P>0.05=$ Non-significant
P1: Comparison between pre and post-implementing program, $P \leq 0.05=$ Significant 
Table (3): The total mean score percentage of the studied critical care nurses practice pre and post of endotracheal tube care implementation $($ No. $=60)$.

\begin{tabular}{|c|c|c|c|c|c|c|c|}
\hline \multirow{4}{*}{ Nurses practice } & \multicolumn{6}{|c|}{ Units } & \multirow{4}{*}{ P 1-value } \\
\hline & \multicolumn{3}{|c|}{ Trauma ICU $($ No.=41) } & \multicolumn{3}{|c|}{ General ICU (No.=17) } & \\
\hline & \multicolumn{2}{|c|}{ Mean \pm S.D } & \multirow[b]{2}{*}{ P-value } & \multicolumn{2}{|c|}{ Mean \pm S.D } & \multirow[b]{2}{*}{ P-value } & \\
\hline & $\begin{array}{c}\text { Pre- } \\
\text { implementing }\end{array}$ & $\begin{array}{c}\text { Post- } \\
\text { implementing }\end{array}$ & & $\begin{array}{c}\text { Pre- } \\
\text { implementing }\end{array}$ & $\begin{array}{c}\text { Post- } \\
\text { implementing }\end{array}$ & & \\
\hline $\begin{array}{l}\text { Endotracheal tube } \\
\text { care assessment }\end{array}$ & $2.7 \pm 1.06$ & $4.19 \pm .85$ & $<.000$ & $2.24 \pm 0.56$ & $3.94 \pm .83$ & $<.000^{*}$ & $<.001 *$ \\
\hline \multicolumn{8}{|l|}{ Prepare equipment } \\
\hline $\begin{array}{l}\text { endotracheal } \\
\text { tube care }\end{array}$ & $5.67 \pm 0.99$ & $6.84 \pm .95$ & $<.001 *$ & $5.35 \pm-0.86$ & $6.41 \pm 1.06$ & $<.005^{*}$ & $<.001 *$ \\
\hline $\begin{array}{l}\text { arterial blood } \\
\text { gas analysis }\end{array}$ & $5.37 \pm 1.92$ & $7.51 \pm 1.71$ & $<.000 *$ & $4.24 \pm 1.79$ & $6.94 \pm 1.68$ & $<.000^{*}$ & $<.001 *$ \\
\hline oral care & $4.21 \pm .91$ & $5.14 \pm .99$ & $<.002 *$ & $4.47 \pm 0.80$ & $5.41 \pm 0.87$ & $<.001 *$ & $<.001 *$ \\
\hline $\begin{array}{l}\text { endotracheal } \\
\text { suctioning }\end{array}$ & $6.91 \pm 1.31$ & $8.07 \pm .99$ & $<.001 *$ & $6.35 \pm 1.46$ & $7.76 \pm 1.35$ & $<.006^{*}$ & $<.001 *$ \\
\hline \multicolumn{8}{|l|}{ Application } \\
\hline $\begin{array}{l}\text { Endotracheal } \\
\text { tube care }\end{array}$ & $8.95 \pm 2.30$ & $13.86 \pm 1.77$ & $<.001 *$ & $8.29 \pm 1.80$ & $13.35 \pm 2.03$ & $<.000^{*}$ & $<.001 *$ \\
\hline $\begin{array}{l}\text { Arterial blood } \\
\text { gas analysis }\end{array}$ & $10.16 \pm 1.94$ & $12.81 \pm 2.66$ & $<.000 *$ & $9.47 \pm 2.07$ & $12.29 \pm 2.52$ & $<.003^{*}$ & $<.001 *$ \\
\hline $\begin{array}{l}\text { Endotracheal } \\
\text { tube cuff care }\end{array}$ & $7.44 \pm 2.20$ & $13.86 \pm 1.77$ & $<.001 *$ & $8 \pm 2.45$ & $13.35 \pm 2.03$ & $<.000 *$ & $<.001 *$ \\
\hline $\begin{array}{l}\text { Oral care } \\
\text { procedure }\end{array}$ & $8.09 \pm 1.60$ & $10.14 \pm 1.91$ & $<.001 *$ & $7.18 \pm 1.19$ & $9.41 \pm 1.84$ & $<.001 *$ & $<.001 *$ \\
\hline $\begin{array}{l}\text { Endotracheal } \\
\text { suctioning }\end{array}$ & $12.56 \pm 2.39$ & $16.21 \pm 2.03$ & $<.001 *$ & $12 \pm 3.20$ & $15.88 \pm 1.27$ & $<.000^{*}$ & $<.001 *$ \\
\hline $\begin{array}{l}\text { Mechanical } \\
\text { ventilation }\end{array}$ & $3 \pm 1.43$ & $4.86 \pm 1.23$ & $<.000 *$ & $2.47 \pm 0.72$ & $4.47 \pm 1.46$ & $<.000^{*}$ & $<.001 *$ \\
\hline Reevaluation & $2.67 \pm 0.87$ & $3.91 \pm .0 .68$ & $<.000 *$ & $3.06 \pm 0.75$ & $3.82 \pm 0.73$ & $<.018^{*}$ & $<.001 *$ \\
\hline Documentation & $2.63 \pm 0.62$ & $6.40 \pm 1.92$ & $<.000 *$ & $3 \pm 0.71$ & $6.24 \pm 2.33$ & $<.000^{*}$ & $<.001 *$ \\
\hline $\begin{array}{l}\text { Overall total } \\
\text { practice scores (163) }\end{array}$ & $80.37 \pm 9.2$ & $113.79 \pm 10.7$ & $<.000 *$ & $76.12 \pm 7.4$ & $109.29 \pm 10.9$ & $<.000^{*}$ & $<.001 *$ \\
\hline
\end{tabular}

P1: Comparison between pre and post-implementing program.

$P \leq 0.05=$ Significant

Paired sample t-test

$P>0.05=$ Non-significant

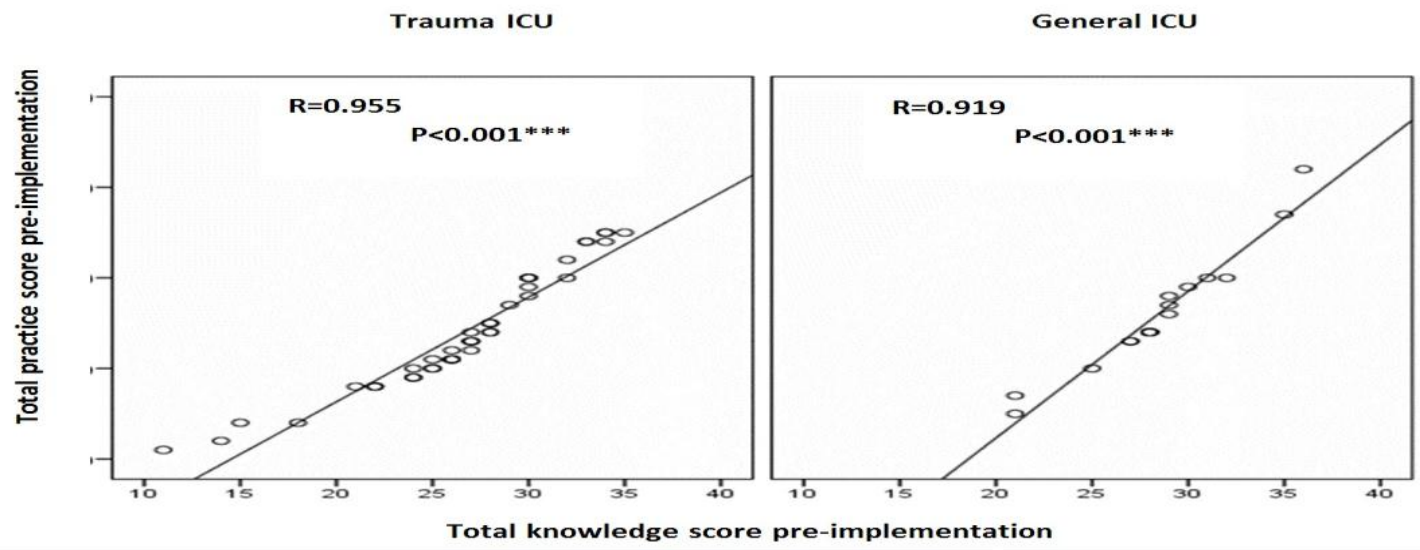

Fig. (1): Correlation between pre-knowledge score and pre-practice scores of nursing personnel regarding endotracheal tube care. 


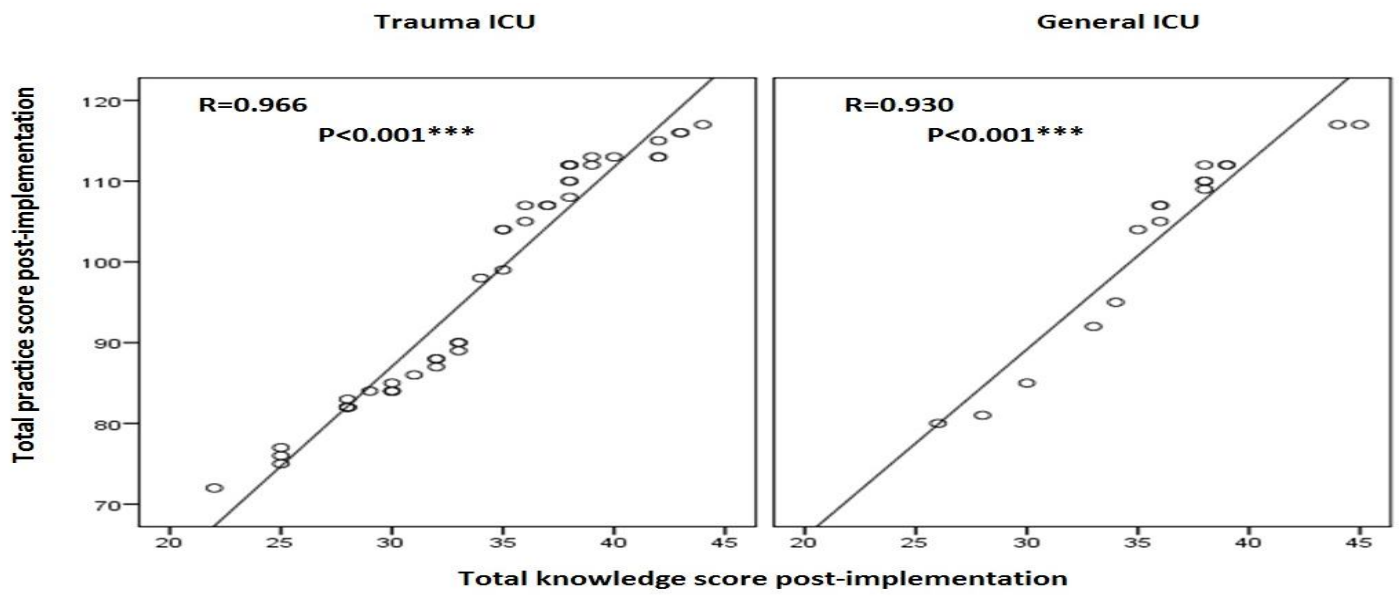

Fig (2): Correlation between post-knowledge score and post-practice scores of nursing personnel regarding endotracheal tube care.

Table (4): Distribution of the studied critically ill patients according to their characteristics.

\begin{tabular}{|c|c|c|c|c|c|}
\hline \multirow[t]{2}{*}{ Sociodemographic data } & \multicolumn{2}{|c|}{$\begin{array}{c}\text { Patient (60) } \\
\text { Pre-implementing }\end{array}$} & \multicolumn{2}{|c|}{$\begin{array}{c}\text { Patient (60) } \\
\text { Pre-implementing }\end{array}$} & \multirow[t]{2}{*}{ P-value } \\
\hline & No. & $\%$ & No. & $\%$ & \\
\hline \multicolumn{5}{|l|}{ Age:(years) } & \multirow{4}{*}{0.762} \\
\hline $18<30$ & 29 & 48.4 & 25 & 41.6 & \\
\hline $30<45$ & 18 & 30 & 20 & 33.4 & \\
\hline $45<60$ & 13 & 21.6 & 15 & 25 & \\
\hline $\mathrm{X} \pm \mathrm{SD}$ & \multicolumn{2}{|c|}{$33.12 \pm 12.38$} & \multicolumn{2}{|c|}{$33.83 \pm 12.03$} & 0.748 \\
\hline \multicolumn{6}{|l|}{ Medical diagnosis: } \\
\hline Chest injury & 7 & 11.6 & 17 & 28.4 & \multirow{5}{*}{0.143} \\
\hline Head injury & 36 & 60 & 32 & 53.4 & \\
\hline Post arrest & 2 & 3.4 & 3 & 5 & \\
\hline Post operation & 5 & 8.4 & 4 & 6.6 & \\
\hline Other & 10 & 16.6 & 4 & 6.6 & \\
\hline
\end{tabular}

Chi-square test

$P \leq 0.05=$ Significant
Independent sample t-test

$P>0.05=$ Non-significant

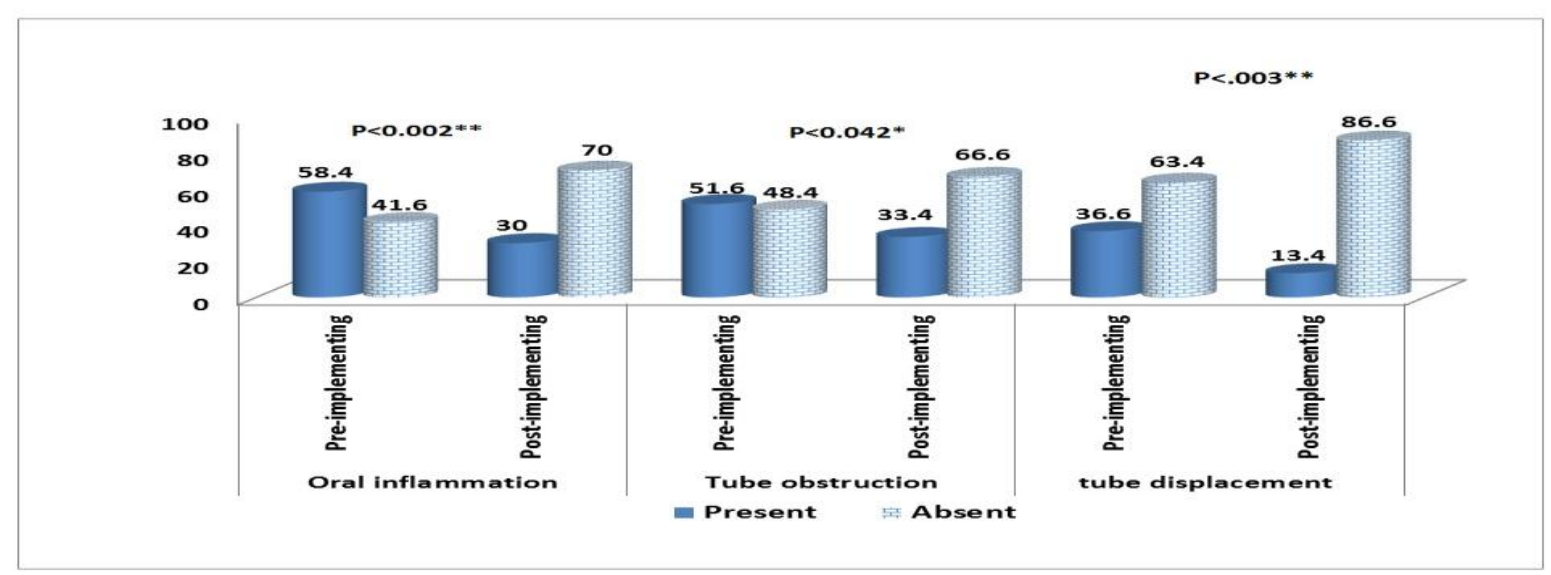

Fig. (3): Comparison between patient's complications as regard pre and post implementing endotracheal tube care program. 
Table (1) show that, the studied sample consists of 60nurses (43 were from trauma intensive care unit and 17 from the general intensive care unit). As regard to age, the majority of trauma intensive care unit nurses were more than 25 and less than 30 (40\%) and the majority of general intensive care unit nurses were less than $25 y$ rs $(15 \%)$. As regard to marital status, the majority of both traumatic and general intensive care unit nurses were single (43.3\%), (16.7\%). Trauma intensive care unit, nursing bachelor's was the highest proportion (26.7\%), General intensive care unit, the nursing diploma was the highest proportion (15\%). (26.7\%) of nurses had an experience more than 5 years and less than 10 years in trauma intensive care unit but $(11.7 \%)$ of nurses had an experience less than one years, in general, intensive care unit. As regard, the majority of nurses in both units' nurses have not attended any previous training courses about the endotracheal tube. Hypothesis (1): Post mean knowledge scores of nurses will be higher than pre mean knowledge scores.

Table (2): this table shows The total mean score percentage of the studied critical care nurses level of knowledge pre and post of endotracheal tube care implementation:-

- There was a significant difference in nurses' mean knowledge about endotracheal intubation $(\mathrm{P}<0.001)$ in the trauma and general ICU nurses. In addition, there was a significant difference in nurses' mean knowledge about preparation endotracheal intubation $(\mathrm{P}<0.002)$.

- Showed was significant difference in nurses' mean knowledge about after endotracheal intubation care $(\mathrm{P}<0.001)$ in the trauma and general ICU nurses

- Showed was a significant difference in trauma ICU nurses' mean knowledge about Infection control $(\mathrm{P}<0.004)$.

- Showed was significant difference in nurses' total mean knowledge about endotracheal intubation $(\mathrm{P}<0.001)$ in the trauma and general ICU nurses

Hypothesis (2):

The post-practice score of nurses will be higher than the pre mean practice scores.

Table (3) shows the total mean score percentage of the studied critical care nurses level of practice pre and post of endotracheal tube care implementation:

- There was the significant difference in nurses' practice about endotracheal tube care assessment $(\mathrm{P}<0.001)$ in both trauma and general ICU.
- There was a significant difference in nurses' practice about sub title of prepare equipment care $(\mathrm{P}<0.001)$ both trauma and general ICU.

- There was a significant difference in nurses' practice about sub title of application of endotracheal tube care $(\mathrm{P}<0.001)$ both trauma and general ICU.

- There was the significant difference in nurses' practice about reevaluation endotracheal tube care $(\mathrm{P}<0.001)$ in both trauma and general ICU.

- There was the significant difference in nurses' practice about Documentation endotracheal tube care $(\mathrm{P}<0.001)$ in both trauma and general ICU.

- Showed was significant difference in nurses' total mean practice about endotracheal intubation $(\mathrm{P}<0.001)$ in the trauma and general ICU nurses

Hypothesis (3):

A positive relationship will exist between knowledge and practice score obtained by nurses who had developed endotracheal tube.

Figures (1): Showed that correlation between preknowledge score and pre-practice scores of nursing personnel regarding endotracheal tube care: there was positive correlation between total pre knowledge and total pre practice $(\mathrm{r}=0.955)$ for trauma intensive care unit. Also, was positive correlation between total pre knowledge \& total pre practice $(\mathrm{r}=0.991)$ for the general intensive care unit.

Figures (2) Showed that correlation between postknowledge score and post-practice scores of nursing personnel regarding endotracheal tube care: there was positive correlation between total post knowledge \& total post practice $(\mathrm{r}=0.966)$ for trauma intensive care unit. Also was positive correlation between total post knowledge and total post practice $(r=0.903)$ for the general intensive care unit.

Table (4): Showed that distribution of the studied critically ill patients according to their characteristics as regard pre and post implementing endotracheal tube care: they were $24.2 \%$ and $20.8 \%$ of the pre-implementing and postimplementing groups were in the age group of 18 to less than 30 years old. In addition, $30 \%$ and $26.7 \%$ of both groups were diagnosed as having head injury respectively. No significant statistical difference was noticed between the two studied groups in relation to age and diagnosis.

Hypothesis (4)

The incidence of endotracheal tube complication for patient who had endotracheal tube care implementation will be less than that pre implementation care

Figure (3) Showed that comparison between patient's complications as regard pre and post 
implementing endotracheal tube care program: there was significant difference between complication of patient as regard pre \& post implementing endotracheal tube care with oral inflammation $(\mathrm{P}<.002)$, tube obstruction $(\mathrm{P}<.042)$ and tube displacement $(\mathrm{P}<.003)$.

\section{Discussion}

The post-intubation period is an important and often underappreciated phase in emergency airway management. Patients requiring emergency airway management often have limited physiologic reserve, and despite successful placement of an endotracheal tube (ETT) procedure-associated, adverse events arc common. These must be immediately recognized and addressed, as the critically ill patient often has a reduced ability to tolerate even minor physiologic challenges (Kovacs \& Law 2011).

The education and training are two components of staff development that occur after nurses' indoctrination. The staff knowledge level and capabilities are a major factor in determining the number of staffs required to carry out unit goals. The better trained and more competent the staff, the fewer staff required, which in turn saves the organization money and rise reproductively. Education programs are considered for providing nurses with theoretical and technical information needed to acquire new skills and to continually improve their nursing practice. They also help them to accept their reasonability for their professional development (Clement 2011).

The aim of the study to measure the impact of an educational training programme on nurses practice for the patient undergoing endotracheal tube.

El-Eslam(2011) stated that education and training programs for nurses, help to investigate both the current practice and educational requirements of nursing staff for continuous up-dating knowledge and skills to improve the quality of care .

The present study was conducted on a sample of 60 nurses who working in (43 from trauma intensive care unit, 17 from the general intensive care unit). The majority of nurses graduated from diploma and technical nursing from both trauma and general intensive care unit. In addition, the majority of them have not reported previous attendance of training courses related endotracheal tube care. Therefore, nurses were assessed before the program and evaluated after program during actual work. Almost half of the nurses in the present study had more than 5 to 10 years' experience.

These results are in an agreement with Abolwafa et al. (2013), who reported that the studied sample had a higher percentage of knowledge of nurses who had medium experience and have a diploma . Also, Nair (2006), who reported percentage distribution of staff nurses according to the age in completed years show that the highest percentage of the respondents were in the age group, 20-30years.

As regarding knowledge of endotracheal intubation, the present study found that the majority of nurses had poor knowledge level in pre-implementation, they improved the post-implementation program. They explained the reason of lack of knowledge of endotracheal intubation which including insufficient knowledge among staff about endotracheal tube care, and lack training program. These findings agreed with Sharma et al., (2014), who stated that in order for effective patient education to take place the nurse needs an optimum knowledge of endotracheal suctioning.

As regarding, nurse's role after endotracheal intubation according to the study finding, the majority of nurses had lack knowledge before the implementing program. This poor baseline knowledge noticed among nurses might be attributed to that, after graduation, nurses abandon reading and neglect to update their professional knowledge. After the program, the post implementation has shown statistically significant improvement for knowledge. The present study findings is agreement with Marykutty (2012), who reported very poor nurse's knowledge level before exposure to designated educational programs, which significantly and immediately improved after the application of the programs about post tracheostomy intubation.

The findings of the present study indicated that the mean post-implementation knowledge score in all areas of knowledge questionnaire was significantly higher than the mean pre-implementation knowledge score $(\mathrm{P}<0.001)$. The improvement may be due to the present stress the acquisition of knowledge of endotracheal tube care but also it stressed the practical training to gain information and change work practice using adequate sessions and achievement of desired objectives.

Also, these results are congruent with Mathew (2012), who is findings were partially consistent with the findings of an evaluatory study done to assess the effectiveness of planned teaching programe on knowledge of endotracheal suctioning among half of staff nurses. The overall mean post-test knowledge score (27.5) after teaching and mean post-test practice score (28.7) was significantly higher than the overall mean pre-test knowledge score effective in terms of gain in knowledge.

Motivation is one of the most important factors affecting knowledge-for the training program. All participant nurses have taken booklet and handouts for the program objectives and content as well as 
sufficient materials and supplies were provided for the trainers.

Regarding to nursing practice, the present study revealed that before the program, two nurses' practice was adequate and they had scores more than $60 \%$ in all procedures. The finding of the current study can be explained that the reasons for nurse's inadequate practice namely lack in- service training and lack presence of clinical manual for critical care procedure as references. Immediately after the program, nurse's total average percentage for nurses' practice in the different nursing procedure was $(86.6 \%)$.

In regarding endotracheal assessment technique, the result of the present study revealed that the majority of nurses had an inadequate level of practice preimplementing program. The present study lies with de Lima et al., (2013), who found that the mean percentage of nurse's practice regarding oral assessment was very poor before program implementation.

The results of the current study revealed that the instructional program had a positive impact in the improvement of the nursing practice regarding endotracheal tube care procedure and this improvement was sustainable immediately after the instructional program. The findings of the current study were similar to with Sharma et al. (2014), who noticed improvement of nurses' practice as a result of implementing an educational or training program. In a study concerned with endotracheal tube suctioning care, Shubhashini (2007), noticed improvement in practices of endotracheal tube suctioning after the conduction of the program.

Endotracheal suction to maintain airway patency is necessary for the care of the intubated patient and it is frequently carried out, as a routine nursing practice it is primary purpose is to remove airway secretions thereby preventing obstruction, atelectasis, and decrease lung compliance whilst optimizing oxygenation and ventilation El-Eslam (2011). The present study revealed that the majority of nurses practiced endotracheal suctioning inadequately in the pre-implementing program and this was significantly improved after post-implementing program. in this respect this finding agreed with other research studies Sharma et al. (2014), who showed that the mean post-test skill score was significantly higher than the mean pre-test skill score.

Oral care is an important component of critical care nursing, but it is often given a low priority when compared with other practices and interventions Illsley (2012). The present study showed was that the majority of nurses mean score regarding oral care procedure in pre-implementing lesser than those of the post-implementing practice score with highly statistical significantly. The findings of another study,
Jam Gatell et al., (2012), found educational intervention improved ICU nurses' practice about oral hygiene

Proper inflation of the endotracheal tube cuff during mechanical ventilation is of vital importance in ensuring adequate ventilation and preventing the complications of intubation (Maboudi et al., 2013). In the present study, the majority of studied nurses showed significant difference between the mean of pre- implementing and post- implementing practice scores regarding the endotracheal tube cuff pressure procedure. This result agreed with of other research study of Penitenti et al., (2010), who showed improvement of practice level after training program intervention than pre practice level an about endotracheal tube cuff.

The majority of nursing staff did not measure endotracheal tube cuff pressure at pre-program by an objective means; this may be due to unavailability of cuff inflator device in the intended around endotracheal tube cuff, insufficient knowledge among staff about procedure and absence of supervision and lack of training program (Seliman \& El-Soussi, 2011).

As regarding, nurse's reevaluation for patients after procedures according to the study finding, the quarter of nurses assessment before the implementing program. After the program, the post implementation has shown statistically significant improvement for practice. The present study finding is agreed with Jansson et al., (2013), who observed post endotracheal-suctioning assessment practices was significantly lower than the required quality of care. As regards nurses' documentations, the present study revealed that was majority of studied nurses had inadequate procedures at the pre-implementing program. This result improved the post-implementing program, this present result was congruent with Winton et al., (2009), who found improved endotracheal tube care documentation following the implementing program.

Regarding the correlation between total knowledge and practice pre the endotracheal tube care implementation, the result of the current study revealed significant correlation. While postimplementation, there was a significant correlation between total knowledge and total practice. This result agreed with Ross \& Crumpler (2007), who indicated that providing oral care education increases the frequency of performing oral care for practices and consequently improves the quality of oral care for patients with oral endotracheal intubation.

The results of present study showed that the studied patient's pre implementation endotracheal tube care such as oral inflammation and tube obstruction in which all of these complications are reduced in the 
studied patients post endotracheal tube care with statistically significant difference.

As regarded oral inflammation, the results of the present study showed that more than half of patient's pre and one-third post endotracheal tube care suffer from oral inflammation. This result agreed with Fitch \& Munro (1999), who reported the oral inflammation was an improvement after protocol implementation by nurses. Therefore, the oral inflammation was significantly lower in the study group than in the control group $(\mathrm{P}<.03)$.

\section{Conclusion}

Based on the result of the present study, it was concluded that there was the highly statistically significant difference between the nurse knowledge and practice in pre and post-implementing program. Improving nurses' knowledge and practice have a favorable effect in preventing or reducing postendotracheal tube care complications.

\section{Recommendations}

Based on results of the present study the following be recommended:

\section{For nurses}

1. Continued nursing education and in service training programs at intensive care units should be organized within Assiut University Hospital and equipped with the necessary educational facilitators and materials necessary to upgrade the knowledge and practices of practicing nurses, which will be reflected on the better outcome for patients.

2. Nurses could be more motivated to have a better practice in their work.

3. Nurses should be aware by post endotracheal tube care complications, how to prevent it and how to deal with it when to develop.

\section{For administration}

1. Adequate supplies and facilities should be available in the unit.

2. Newly employ nurses in traumatic and general intensive care units are required to successfully complete a test of basic knowledge and practice before assuming independent responsibility for patient care.

\section{For further and researcher}

Replication of the study on a larger probability sample acquired from the different geographical area in Egypt to figure out the main aspects of this problems.

\section{References}

1. Divatia J., Khan P., and Myatra S. (2011): Tracheal intubation in the ICU: Lifesaving or life threatening? Indian Journal of Anesthesia. 55(5): Pp470-475.

2. Agr, F., (2011): Airway management. , pp.91104. https://ambulance.qld.gov.au/docs/02_cpp_air way.

3. Urden, L., Stacy, K., \& Lough, M., (2014): Critical Care Nursing, diagnosis \& treatment, $6^{\text {th }}$ ed., Elsevier Mosby. Available at www.amazon.com

4. Jansson, M., (2014): The effectiveness of education on critical care nurses' knowledge \& skills in adhering to guidelines to prevent ventilator-associated pneumonia. pp. 53-60

5. Miller R., \& Pardo M., (2011): Basics of Anesthesia, 6th ed., Elsevier stander

6. Kovacs, G., \& Law, J., (2011): Airway Management in Emergencies (2nd ed., p. 454). People's Medical Publishing House-USA. Retrieved fromww.info@pmph-usa-USA

7. Clement, I., (2011): Management of Nursing Services and Education (Vol. 20, p. 208). Elsevier India.

8. El-Eslam, R., (2011): the impact of implementing infection control program for nurses to control nasocomial infection in neonatal intensive care units port said. Alexandria Scientific Nursing Journal, 12(1), Pr.1-32.

9. Abolwaf, N., Ouda, W., Mohammed, F., \& Masoed, E., (2013): Developing an educational program for nurses' related to infection control of invasive procedures in neonatal units at EL-Minia university and general hospitals, Journal of American Science, 9(10), Pp. 286-293.

10. Nair, B., (2006): A study to evaluate the effectiveness of a self instructional module ( $\operatorname{sim}$ ) on nursing management of patients with chest tube drainage for staff nurses in a selected hospital at mangalore, (i).

11. Sharma, S., Sarin, J., \& Bala, G., (2014): The effectiveness of " endotracheal suctioning protocol " in terms of knowledge and practices of nursing personnel. Nursing and Midwifery Research Journal, 10(2), Pr.47-60.

12. Marykutty, K., (2012): "A study to evaluate the effectiveness of planned teaching programme regarding tracheostomy care in terms of knowledge of staff nurses working in government hospital Tumkur ". Rajiv gandhi university of health sciences, pp. 60-80. 
13. Mathew B., (2012): The effectiveness of planned teaching programme on knowledge and practices of endotracheal suctioning procedure among staff nurses in the different units of selected hospital in Mangalore. Unpublished Masters in Nursing dissertation submitted to RGUHS, Bangalore.

14. De Lima, E., Fleck, C., Borges, J., Condessa, R., \& Vieira, S., (2013): Effects of educational intervention on adherence to the technical recommendations for tracheobronchial aspiration in patients admitted to an intensive care unit. Revista Brasileira de Terapia Intensiva, 25(2), PP 115-22.

15. Shubhashini, S., (2007): The effectiveness of learning package regarding care of a patient on a mechanical ventilator to the staff nurses of a selected hospital in mangalore.

16. Illsley, A., (2012): Mouth Care Guideline Within Adult Critical Care. Nottingham University Hospital, PP1-18.

17. Jam Gatell, M., Santé Roig, M., Hernández Vian, Ó., Carrillo Santín, E., Turégano Duaso, C., Fernández Moreno, I., \& Vallés Daunis, J., (2012): Assessment of a training programme for the prevention of ventilatorassociated pneumonia. Nursing in Critical Care, 17(6), Pp285-92.

18. Maboudi, A., Abtahi, H., Hosseini, M., Tamadon, A., \& Safavi, E., (2013): The accuracy of endotracheal tube cuff pressure adjustment by fingertip palpation after training of intensive care unit nurses. Iranian Red Crescent Medical Journal, 15(5), PP 381-4.

19. Penitenti, R., \& Vilches, J., (2010): Cuff pressure control in intensive care unit: training effects. Revista Brasileira de ..., 22(2), Pp192195.

20. Seliman, A., \& El-Soussi, A., (2011): Effect of implementing nursing guidelines for tube feeding on the occurrence of aspiration among critically ill patients. Nature \& Science, 9(11), Pp164-175.

21. Jansson, M., Ala-Kokko, T., Ylipalosaari, P., \& Kyngäs, H., (2013): Evaluation of endotracheal-suctioning practices of criticalcare nurses - An observational correlation study. Journal of Nursing Education and Practice, 3(7), PP99-105.

22. Winton, J., Celenza, A., \& Jackson, T., (2009): Improving documentation of endotracheal intubation in an adult emergency department. Journal Compilation (C) 2008 Australasian College for Emergency Medicine and Australasian Society for Emergency Medicine, 20(6), Pp 488-493.
23. Ross, A., \& Crumpler, J., (2007): The impact of an evidence-based practice education program on the role of oral care in the prevention of ventilator-associated pneumonia. intensive \& critical care nursing: The Official Journal of the British Association of Critical Care Nurses, 23(3), Pp 132-6.

24. Fitch, J., \& Munro, C., (1999): Oral care in the adult intensive care unit. American Journal of Critical Care, 8(5), pp 1-15. 